\title{
The Schools' Activity Confidence Eating Project: a qualitative evaluation
}

\author{
D. Tynan ${ }^{1}$, J. Kearney ${ }^{1}$, C. Johnston Molloy ${ }^{2}$, S. Kleemann ${ }^{2}$, C. Glennon Slattery ${ }^{2}$ and M. Murtagh ${ }^{2}$ \\ ${ }^{1}$ Dublin Institute of Technology, Kevin Street, Dublin 8, Republic of Ireland and ${ }^{2}$ Community Nutrition and \\ Dietetic Service, Health Service Executive, Dublin Mid-Leinster, Marlinstown Office Park, Mullingar, \\ Co. Westmeath, Republic of Ireland
}

The primary school has proved a valuable setting in which to promote health and health awareness amongst children ${ }^{(1)}$. Primary schoolchildren tend to be more susceptible to health messages being advocated and may maintain such lifestyle changes into adolescence and adulthood $^{2}$. The Schools' Activity Confidence Eating (ACE) Project is a school-based health initiative focused on four prime health aspects encompassing nutrition, physical activity, dental health and mental health. This project aims to promote health and health awareness of pupils with the aid of two Schools' ACE supporters, two specifically-trained community nutrition assistants who facilitate and empower each school in developing their own health policy, integrating this health policy within the school curriculum and sustaining the policy and its objectives. The primary aim of the present study was to qualitatively assess the thoughts, attitudes and opinions of parents, pupils, teaching staff and ACE supporters involved with the Schools' ACE project, on the project itself and on the role of the two Schools' ACE supporters.

In order to assess these variables focus-group discussions with each participating school $(n 3)$ in conjunction with in-depth interviews $(n 4)$ were employed. A short self-report questionnaire, using both open and closed questions, was also completed by each individual involved within focus-group discussions ( $n$ 15) in order to verify statements made in each focus group and to allow for individual response.

All participants perceived the Schools' ACE project to be a beneficial health initiative for pupils, teaching staff and parents involved ( $n$ 19). Increased nutrition education and physical activity, post intervention of the Schools' ACE Project, was reported by both teachers and parents involved. This outcome corresponded to a reported increase in health awareness and improved weight and behaviour management in pupils. Teachers, pupils and parents noted the Schools' ACE supporters to be beneficial in the provision of support, resources and information and in maintaining progression of the project within the school setting. The primary implementation challenges discussed included: time constraints and increased workload for teaching staff; policing of the policy within the school setting and the predicament of whether to ban specific food items. The importance of support from teachers, parents, pupils and Schools' ACE supporters was clearly defined by all participants $(n 19)$ as key to the success of the project. The Table outlines participant suggestions for improvement of the Schools' ACE project.

\begin{tabular}{l}
\hline Participant suggestions \\
\hline Further parental education \\
Further teacher training \\
Increased interactive demonstrations and activities for pupils \\
Defining roles of each individual more clearly \\
\hline
\end{tabular}

Such participant input offers the potential for future enhancement of the Schools' ACE Project and improvements in its efficacy to be made.

1. Pérez-Rodrigo C \& Aranceta J (2001) Public Health Nutr 4, 131-139.

2. Sahota P, Rudolf CJ, Dixey R, et al. (2001) Br Med J 323, 1029. 